\title{
Fluctuations in Cytosolic Calcium Regulate the Neuronal Malate- Aspartate NADH Shuttle: Implications for Neuronal Energy Metabolism
}

\author{
Jorgina Satrústegui ${ }^{1,2,3} \cdot$ Lasse K. Bak ${ }^{4}$
}

Received: 16 March 2015/Revised: 15 May 2015 / Accepted: 23 June 2015/Published online: 3 July 2015

(C) Springer Science+Business Media New York 2015

\begin{abstract}
The malate-aspartate NADH shuttle (MAS) operates in neurons and other cells to translocate reducing equivalents from the cytosol to the mitochondrial matrix, thus allowing a continued flux through the glycolytic pathway and metabolism of extracellular lactate. Recent discoveries have taught us that MAS is regulated by fluctuations in cytosolic $\mathrm{Ca}^{2+}$ levels, and that this regulation is required to maintain a tight coupling between neuronal activity and mitochondrial respiration and oxidative phosphorylation. At cytosolic $\mathrm{Ca}^{2+}$ fluctuations below the threshold of the mitochondrial calcium uniporter, there is a positive correlation between $\mathrm{Ca}^{2+}$ and MAS activity; however, if cytosolic $\mathrm{Ca}^{2+}$ increases above the threshold, MAS activity is thought to be reduced by an intricate mechanism. The latter forces the neurons to partly rely on anaerobic glycolysis producing lactate that may be metabolized subsequently, by neurons or other cells. In this
\end{abstract}

Special Issue: In honor of Dr. Gerald Dienel.

Jorgina Satrústegui

jsatrustegui@cbm.csic.es

Lasse K. Bak

laba@sund.ku.dk

1 Departamento de Biología Molecular, Centro de Biología Molecular Severo Ochoa, Consejo Superior de Investigaciones Científicas-Universidad Autónoma de Madrid, 28049 Madrid, Spain

2 Centro de Investigación Biomédica en Red de Enfermedades Raras, 28049 Madrid, Spain

3 Instituto de Investigación Sanitaria Fundación Jiménez Díaz, 28040 Madrid, Spain

4 Department of Drug Design and Pharmacology, Faculty of Health and Medical Sciences, University of Copenhagen, 2100 Copenhagen, Denmark review, we will discuss the evidence for $\mathrm{Ca}^{2+}$-mediated regulation of MAS that have been uncovered over the last decade or so, together with the need for further verification, and examine the metabolic ramifications for neurons.

Keywords Mitochondria $\cdot$ Malate-aspartate NADH shuttle $\cdot$ Calcium $\cdot$ Neuron $\cdot$ Metabolism

\section{Introduction}

The malate-aspartate NADH shuttle (MAS) is the main pathway whereby reducing equivalents from cytosolic NADH are transferred to mitochondria. It is composed of two sets of enzymes, malate dehydrogenase and aspartate aminotransferase each with mitochondrial and cytosolic localization, and two mitochondrial carriers, that of oxoglutarate/malate, OGC/Slc25a11 and those of aspartate/ glutamate, the AGCs. The AGCs have two isoforms in mammals, AGC1/aralar/Slc25a12 and AGC2/citrin/Slc25a13 [1], and AGC1 is the main brain isoform [2-4] with only marginal expression of AGC2 in a few brain nuclei [5]. The AGCs belong to a family of $\mathrm{Ca}^{2+}$ activated mitochondrial carriers which stand out because of the presence of EF-hand $\mathrm{Ca}^{2+}$-binding motifs on the N-terminal half of the protein. These motifs face the intermembrane space and can sense extramitochondrial $\mathrm{Ca}^{2+}$ $[2,6,7]$. Most of the glucose utilized by brain neurons is oxidized in mitochondria, and this requires a substantial transfer of reducing equivalents from cytosolic NADH to mitochondria through MAS [8]. In vivo, AGC1 may largely be present in neurons [9] although both mRNA and functional protein has been detected in freshly isolated mouse astrocytes [10], and aralar was identified as an interaction partner to the astrocytic glutamate transport, 
GLT-1 [11]. In this review, we will focus on the role of $\mathrm{Ca}^{2+}$ activation of AGC1-MAS in response to neuronal workloads under conditions of varying intensity stimulation.

\section{Malate-Aspartate Shuttle in Isolated Brain Mitochondria and Intact Neurons: Activation by Fluctuations in Cytosolic $\mathrm{Ca}^{2+}$}

To study the regulation of MAS, Contreras and coworkers reconstituted MAS in isolated brain mitochondria and studied the kinetics of activation by $\mathrm{Ca}^{2+}$ (see references below). MAS is active in a $\mathrm{Ca}^{2+}$-free medium but its activity is increased about three-fold in the presence of extramitochondrial $\mathrm{Ca}^{2+}$, with half maximal activation at $300 \mathrm{nM} \mathrm{Ca}^{2+}$. This involves a change in Vmax, but not the affinity for glutamate $[12,13]$. These experiments were carried out in the presence of ruthenium red, an inhibitor of the mitochondrial $\mathrm{Ca}^{2+}$ uniporter clearly identifying extramitochondrial rather than matrix $\mathrm{Ca}^{2+}$ as the cause of activation. MAS activity feeds reducing equivalents from cytosolic NADH to the matrix and mitochondrial oxygen consumption fueled by glutamate and malate depends on MAS activity [14]; therefore, extramitochondrial $\mathrm{Ca}^{2+}$ activation of MAS is expected to increase respiration on these substrates in isolated mitochondria in the presence of high ADP levels. Indeed, Gellerich and coworkers using high resolution respirometry found exactly that to be the case, with a $\mathrm{Kd}$ for $\mathrm{Ca}^{2+}$ activation of respiration of about $300 \mathrm{nM}$ [15]. $\mathrm{Ca}^{2+}$ activation was independent of the presence of ruthenium red, consistent with a role of extramitochondrial rather than matrix $\mathrm{Ca}^{2+}$ on activation [15]. Further work of Gellerich and coworkers suggested that the main function of MAS activation by $\mathrm{Ca}^{2+}$ in regulating respiration was the control of pyruvate supply [16]. This conclusion was inferred from experiments of MAS reconstitution with brain mitochondria in the presence of lactate and lactate dehydrogenase (LDH). In this system, $\mathrm{Ca}^{2+}$ activation of MAS acted upon the NADH/NAD ${ }^{+}$ couple in the extramitochondrial medium to divert lactate into pyruvate, which then fed mitochondria. In this case, a large part of the $\mathrm{Ca}^{2+}$-dependent increase in respiration was blocked by cinnamate, an inhibitor of pyruvate transport in mitochondria [16]. Therefore, the reducing equivalent transfer through MAS would add to pyruvate supply (also dependent on MAS) to fully increase respiration under these conditions [16]. On the whole, $\mathrm{Ca}^{2+}$-activation of MAS through aralar/AGC1 would provide the neurons (or any cell) with the capacity to increase respiration on pyruvate if needed, acting as a gas pedal $[16,17]$.

However, evidence that these mechanisms really operate in intact neurons with the actual concentrations of substrates was lacking. On the one hand, even with glucose as the main energy source, neuronal mitochondria may face a variety of respiratory substrates [8]. On the other, the role of $\mathrm{Ca}^{2+}$ itself as a regulator of neuronal respiration has been challenged by the finding of a lack of response to $\mathrm{Ca}^{2+}$ in oxygen consumption of cerebellar neurons [18]. These issues have been recently addressed in cerebrocortical neurons using physiological glucose concentrations [19]. Calcium was clearly shown to play a role in regulating workload-stimulated neuronal respiration. Interestingly, MAS played a very important role in this stimulation. The lack of aralar/AGC1 completely suppressed the $\mathrm{Ca}^{2+}$-dependent responses to the small-tomoderate workloads caused by carbachol, which mobilizes endoplasmic reticulum (ER) $\mathrm{Ca}^{2+}$, and $\mathrm{K}^{+}$-depolarization, which allows $\mathrm{Ca}^{2+}$ entry via voltage-gated $\mathrm{Ca}^{2+}$ channels. In both cases the response was restored by the addition of pyruvate, clearly showing a major role of MAS in providing pyruvate via glycolysis to neuronal mitochondria. In fact, even under conditions in which $\mathrm{Ca}^{2+}$ was taken up into mitochondria resulting in increased matrix NADH levels [20] and pyruvate dehydrogenase activation [21], neuronal respiration was not stimulated, indicating that the role played by MAS in increasing pyruvate supply to mitochondria is required to fuel respiration on glucose [22]. MAS activity was also required to respond to the high workload imposed by veratridine, which opens voltagegated $\mathrm{Na}^{+}$channels; in its absence, the large $\mathrm{Ca}^{2+}$-dependent increase in respiration was reduced by $70 \%$, but the residual $30 \%$ increase is most likely due to matrix $\mathrm{Ca}^{2+}$ effects caused after $\mathrm{Ca}^{2+}$ entry in mitochondria [19].

\section{Malate Aspartate Shuttle in Isolated Brain Mitochondria and Intact Neurons: Inhibition by Matrix $\mathrm{Ca}^{2+}$}

Regulation by $\mathrm{Ca}^{2+}$ of reconstituted MAS in brain mitochondria differed if ruthenium red was not included in the assays [12]. In that case, low $\mathrm{Ca}^{2+}$ concentrations still activated MAS, but at higher $\mathrm{Ca}^{2+}$ concentrations in the micromolar range MAS activity decreased [12]. This paradoxical result was not due to mitochondria dysfunction due to the opening of the permeability transition pore caused by high matrix $\mathrm{Ca}^{2+}$, as it was not modified in the presence of cyclosporin. Rather, it was traced to effects of matrix $\mathrm{Ca}^{2+}$ on the second mitochondrial carrier of MAS, the malate oxoglutarate carrier, OGC. Indeed, reconstitution of the OGC in brain mitochondria exposed to different $\mathrm{Ca}^{2+}$ loads in the absence of ruthenium red indicated that the OGC export of $\alpha$-ketoglutarate $(\alpha-K G)$ decreased with the $\mathrm{Ca}^{2+}$ taken up in mitochondria [12]. Interestingly, this effect was reversible, and the activity of the carrier was 
restored after allowing $\mathrm{Ca}^{2+}$ efflux from mitochondria via the $\mathrm{Na}^{+} / \mathrm{Ca}^{2+}$ exchanger [12]. The effect of matrix $\mathrm{Ca}^{2+}$ on the OGC was attributed to matrix $\mathrm{Ca}^{2+}$ activation of $\alpha$-ketoglutarate dehydrogenase $(\alpha-\mathrm{KGDH})$, and consequent inhibition of OGC, as suggested for heart mitochondria [23, 24]. Both activities have similar $\mathrm{Km}$ value for $\alpha-\mathrm{KG}$ (1.5 and $2.1 \mathrm{mM}$ for the OGC and $\alpha-\mathrm{KGDH}$, respectively $[25,26])$. Upon entry through the mitochondrial uniporter, $\mathrm{Ca}^{2+}$ stimulates $\alpha$-KGDH by reducing its $\mathrm{Km}$ value for $\alpha-\mathrm{KG}$ (from 2.1 to $0.16 \mathrm{mM}$, with an $\mathrm{S}_{0.5}$ of around $1.2 \mu \mathrm{M}$ for calcium [25]). In this situation, OGC will be at a disadvantage, and thus $\alpha-K G$ efflux will become impaired (see Fig. 4, Ref. [7]). This competition of the two pathways for a common substrate is consistent with the findings of O'Donnell et al. [23], who reported a fourfold reduction of MAS activity in heart under high workload conditions. However, it must be kept in mind that the experiments on MAS inhibition by matrix $\mathrm{Ca}^{2+}$ in isolated mitochondria were carried out in the absence of pyruvate (or lactate as pyruvate donor). As indicated by Gellerich [16] in isolated mitochondria and by Llorente-Folch et al. [19, 21] and Rueda et al. [22] for intact neurons, the main function of MAS activation is to stimulate pyruvate uptake in mitochondria, and it is possible that the extra supply of pyruvate caused by $\mathrm{Ca}^{2+}$-activation of MAS prevents a fall in $\alpha-K G$ levels and inhibition of the OGC. In fact, Gellerich et al. [16] did not detect any inhibitory effect of $\mathrm{Ca}^{2+}$ on respiration on malate + glutamate within the $10 \mathrm{nM}$ to $1 \mu \mathrm{M}$ range in the presence of lactate as a pyruvate donor. Therefore, in isolated brain mitochondria inhibition of MAS by matrix $\mathrm{Ca}^{2+}$ caused by $\mathrm{Ca}^{2+}$ concentrations up to $1 \mu \mathrm{M}$ probably depends upon the absence of pyruvate supply. However, glucose-derived pyruvate supply may become limiting in intact neurons under conditions of intense workloads and large $\mathrm{Ca}^{2+}$ signals [27]. Therefore, the extent to which the inhibition of OGC by matrix $\mathrm{Ca}^{2+}$ occurs in vivo remains an open question.

The bulk of ATP production in neurons, and indeed most eukaryotic cells, is via oxidative phosphorylation in the mitochondria, with glycolysis providing only a marginal amount of ATP [8]. In neurons, the pyruvate fueling mitochondrial oxidative metabolism may be derived from either glucose or lactate present in the extracellular space [8]. Reversible inhibition of the MAS by intermittent activation of the mitochondrial $\mathrm{Ca}^{2+}$ uniporter and thus fluctuating matrix $\mathrm{Ca}^{2+}$ levels during neurotransmission activity, as shown by Contreras et al. [12], will have a direct effect on the neuron's ability to process glucose and lactate since the production of pyruvate from both glucose and lactate requires a continuous oxidation of cytosolic NADH generated in glycolysis and the LDH-catalyzed reaction, respectively [8]. Thus, what we propose is that during peak neurotransmission in which the (post-synaptic) cytosolic $\mathrm{Ca}^{2+}$ levels rise sufficiently high to surpass the mitochondrial $\mathrm{Ca}^{2+}$ uniporter's threshold for $\mathrm{Ca}^{2+}$ accumulation in the mitochondrial matrix, MAS becomes inhibited due to a $\mathrm{Ca}^{2+}$-induced increase in the affinity of $\alpha-\mathrm{KGDH}$ for the substrate, $\alpha-\mathrm{KG}$, thus competing with the mitochondrial OGC, a key component of the MAS as discussed above $[12,28]$. It is important to note, that in situ the MAS is not likely to be completely but only partially inhibited; in other words, when this mechanism is manifest, it will limit the mitochondria's ability to re-oxidize cytosolic NADH, not completely abolish it.

We have previously independently suggested that this intermittent, reversible inhibition of the MAS leads to the neurons not being able to employ lactate as a substrate during peaks in mitochondrial matrix $\mathrm{Ca}^{2+}[12,28,29]$; on the contrary, they may actually become net producers of lactate contributing to the rise in extracellular lactate observed during neurotransmission activity [30]. The latter is corroborated by an in vivo study in rodent cerebellum showing that inhibition of post-synaptic glutamate receptors abolished increases in extracellular lactate levels induced via climbing fibre stimulation of cerebellar Purkinje cells [31]. We have previously shown that active cultured neurons releases lactate to the extracellular medium [29] and that glucose, but not lactate metabolism is upregulated during neurotransmission activity [28, 32].

This view is not consistent with the 'classical' astrocyteneuron lactate shuttle hypothesis, stating that lactate flows in only one direction, i.e. from astrocytes to neurons [33]. It is, however, consistent with a more nuanced view of lactate dynamics where extracellular lactate originates from, and is metabolized by, multiple cell types, where lactate is scattered from the activated brain area via the astrocytic syncytium [34], and where lactate plays roles other than that of an energy substrate, e.g. redox signaling to switch on neuronal plasticity genes [35]. It still seem appropriate to challenge the conservative and somewhat static view on lactate shuttling between neurons and astrocytes that almost seem to predetermine conclusions from new studies regarding metabolite fluxes, as exemplified by a recent study on the interaction between oligodendrocytes and the axonal compartment of neurons [36, 37]. One issue that remains unsettled in this latter study is the fact that axons metabolizing lactate (or pyruvate) only are not able to operate the pentose phosphate shuttle. Thus, these long neuronal white matter projections cannot synthesize nucleotides and re-oxidize NADPH locally.

However, not all neuronal mitochondria may be affected by $\mathrm{Ca}^{2+}$-induced inhibition of MAS. We know that mitochondria are heterogeneous in terms of their proteome and function among different organs, within organs, and likely within the same cell [38-41]. Is it likely that mitochondria 
within the same neuron are different, or that they experience differences in their cellular environment that causes them to respond distinctly to different stimuli? We know from metabolic labeling experiments that more than one cellular pool of a given metabolite may exist, showing differential turn over rates or distinct access to label other metabolites [42]; these are very likely linked to heterogeneity of mitochondria. Mitochondria are very dynamic organelles in terms of changing their morphology and location within the cell, and it has been shown that moving neuronal mitochondria pauses near sites of high cytosolic $\mathrm{Ca}^{2+}$ levels [43] suggesting that mitochondrial heterogeneity in terms of metabolism may arise due to proximity to $\mathrm{Ca}^{2+}$ microdomains. Based on experiments in cultured neurons, it was suggested that only a subset of the mitochondrial pool in neurons respond to elevations in cytosolic $\mathrm{Ca}^{2+}$ levels, and that those mitochondria that do respond, primarily metabolize glucose-derived pyruvate as compared to that derived from oxidation of lactate by $\mathrm{LDH}$ [29]. Thus, when $\mathrm{Ca}^{2+}$-induced inhibition of MAS is manifest in this subset of mitochondria during neurotransmission activity, the neurons will produce lactate from glucose and release it to the extracellular environment [29].

\section{Concluding Remarks and Future Directions}

As repeatedly pointed out by Gerry Dienel, brain activation involves increased lactate production [44-47]. As mentioned above, a well-known proposal is that during brain activation, lactate is mainly produced by astrocytes, and consumed in neurons $[33,48]$. However, other studies have concluded that neurons still consume glucose during brain activation, and that the excess of lactate produced is probably removed from the brain through the circulation $[45,46,49,50]$. The results of Bak et al. [28, 29] show that neurons may be one of the sites of lactate production during activation, perhaps due to intermittent MAS inhibition under high activating conditions, consistent with the role of matrix $\mathrm{Ca}^{2+}$ on regulation of OGC and MAS [12].

Admittedly, much work needs to be done to clarify the possible role of OGC inhibition by matrix $\mathrm{Ca}^{2+}$ in vivo during brain activation. This has not been experimentally addressed so far. In addition, some of the earlier work on overloaded heart, which indicated an inhibition of the OGC with increasing workload, needs further verification. For example, the original finding of a reduced OGC mediated outflow of $\alpha$-KG from mitochondria in the dobutaminestimulated heart from mongrel dogs was obtained after metabolic labeling with $\left[2-{ }^{13} \mathrm{C}\right]$-acetate [23]. However, in a second study by the same group carried out in rat heart subject to pressure overload after metabolic labeling with $\left[2,4-{ }^{13} \mathrm{C}\right]$-butyrate, OGC activity increased with workload, with no signs of inhibition [51]. This is also consistent with the maintenance or increase in glutamate labeling from $\left[2-{ }^{13} \mathrm{C}\right]$ pyruvate in heart of dobutamine-treated rats [52]. Therefore, it is likely that the choice of animal model, labeling substrate or workload is influencing the results obtained.

Another concern to be added refers to the changes in metabolite levels that may be predicted if OGC activity is inhibited. Under normal, basal conditions MAS is regulated at the level of its only irreversible step in polarized mitochondria, glutamate $+\mathrm{H}^{+}$/aspartate exchange catalyzed by aralar/AGC1. This step has the lowest $\mathrm{V}_{\max }$ of the MAS components [12], is driven by the proton electrochemical gradient, and is the point of regulation by $\mathrm{Ca}^{2+}$. Changes in the activity of the AGC are expected to influence the distribution of glutamate/aspartate between mitochondria and cytosol. A decrease in AGC1 activity would increase cytosolic glutamate but decrease cytosolic aspartate, probably the major pools of these amino acids, suggesting that an increase in the glutamate to aspartate ratio may be an indicator of low AGC and MAS activity. This is the situation in neurons lacking AGC1 [9, 14], and also that observed in different stimulation conditions both in vitro and in vivo ([12]; Table 3). However, the inhibition of MAS by matrix $\mathrm{Ca}^{2+}$ is not due to changes in AGC activity, but to a decrease in OGC activity, which may now become limiting for MAS [12]. If this gives rise to a decrease in cytosolic $\alpha-\mathrm{KG}$, it may affect the much larger cytosolic glutamate pool, but that remains to be established. Thus, much work still needs to be done to clarify the intricate details of $\mathrm{Ca}^{2+}$-mediated regulation of MAS in neurons, and to verify the findings in vivo.

\section{References}

1. Palmieri L, Pardo B, Lasorsa FM, del Arco A, Kobayashi K, Iijima M, Runswick MJ, Walker JE, Saheki T, Satrustegui J, Palmieri F (2001) Citrin and aralar1 are $\mathrm{Ca}(2+)$-stimulated aspartate/glutamate transporters in mitochondria. EMBO $\mathrm{J}$ 20:5060-5069

2. del Arco A, Satrustegui J (1998) Molecular cloning of Aralar, a new member of the mitochondrial carrier superfamily that binds calcium and is present in human muscle and brain. J Biol Chem 273:23327-23334

3. del Arco A, Morcillo J, Martinez-Morales JR, Galian C, Martos V, Bovolenta P, Satrustegui J (2002) Expression of the aspartate/ glutamate mitochondrial carriers aralar1 and citrin during development and in adult rat tissues. Eur $\mathrm{J}$ Biochem/FEBS 269:3313-3320

4. Ramos M, del Arco A, Pardo B, Martinez-Serrano A, MartinezMorales JR, Kobayashi K, Yasuda T, Bogonez E, Bovolenta P, Saheki T, Satrustegui J (2003) Developmental changes in the $\mathrm{Ca}^{2+}$-regulated mitochondrial aspartate-glutamate carrier aralar1 in brain and prominent expression in the spinal cord. Brain Res Dev Brain Res 143:33-46 
5. Contreras L, Urbieta A, Kobayashi K, Saheki T, Satrustegui J (2010) Low levels of citrin (SLC25A13) expression in adult mouse brain restricted to neuronal clusters. J Neurosci Res 88: 1009-1016

6. Del Arco A, Agudo M, Satrustegui J (2000) Characterization of a second member of the subfamily of calcium-binding mitochondrial carriers expressed in human non-excitable tissues. Biochem J 345(Pt 3):725-732

7. Satrustegui J, Pardo B, Del Arco A (2007) Mitochondrial transporters as novel targets for intracellular calcium signaling. Physiol Rev 87:29-67

8. McKenna M, Dienel GA, Sonnewald U, Waagepetersen HS, Schousboe A (2012) Energy metabolism of the brain. In: Brady ST, Siegel GJ, Albers RW, Price DI (eds) Basic neurochmistry, 8th edn. Academic Press, Elsevier, Waltham, pp 200-231

9. Pardo B, Rodrigues TB, Contreras L, Garzon M, Llorente-Folch I, Kobayashi K, Saheki T, Cerdan S, Satrustegui J (2011) Brain glutamine synthesis requires neuronal-born aspartate as amino donor for glial glutamate formation. J Cereb Blood Flow Metab 31:90-101

10. Li B, Hertz L, Peng L (2012) Aralar mRNA and protein levels in neurons and astrocytes freshly isolated from young and adult mouse brain and in maturing cultured astrocytes. Neurochem Int 61:1325-1332

11. Genda EN, Jackson JG, Sheldon AL, Locke SF, Greco TM, O’Donnell JC, Spruce LA, Xiao R, Guo W, Putt M, Seeholzer S, Ischiropoulos H, Robinson MB (2011) Co-compartmentalization of the astroglial glutamate transporter, GLT-1, with glycolytic enzymes and mitochondria. J Neurosci 31:18275-18288

12. Contreras L, Satrustegui J (2009) Calcium signaling in brain mitochondria: interplay of malate aspartate NADH shuttle and calcium uniporter/mitochondrial dehydrogenase pathways. J Biol Chem 284:7091-7099

13. Contreras L, Gomez-Puertas P, Iijima M, Kobayashi K, Saheki T, Satrustegui J (2007) $\mathrm{Ca}^{2+}$ Activation kinetics of the two aspartate-glutamate mitochondrial carriers, aralar and citrin: role in the heart malate-aspartate NADH shuttle. J Biol Chem 282: 7098-7106

14. Jalil MA, Begum L, Contreras L, Pardo B, Iijima M, Li MX, Ramos M, Marmol P, Horiuchi M, Shimotsu K, Nakagawa S, Okubo A, Sameshima M, Isashiki Y, Del Arco A, Kobayashi K, Satrustegui J, Saheki T (2005) Reduced N-acetylaspartate levels in mice lacking aralar, a brain- and muscle-type mitochondrial aspartate-glutamate carrier. J Biol Chem 280:31333-31339

15. Gellerich FN, Gizatullina Z, Arandarcikaite O, Jerzembek D, Vielhaber S, Seppet E, Striggow F (2009) Extramitochondrial $\mathrm{Ca}^{2+}$ in the nanomolar range regulates glutamate-dependent oxidative phosphorylation on demand. PLoS ONE 4:e8181

16. Gellerich FN, Gizatullina Z, Trumbekaite S, Korzeniewski B, Gaynutdinov T, Seppet E, Vielhaber S, Heinze HJ, Striggow F (2012) Cytosolic $\mathrm{Ca}^{2+}$ regulates the energization of isolated brain mitochondria by formation of pyruvate through the malate-aspartate shuttle. Biochem J 443:747-755

17. Gellerich FN, Gizatullina Z, Gainutdinov T, Muth K, Seppet E, Orynbayeva Z, Vielhaber S (2013) The control of brain mitochondrial energization by cytosolic calcium: the mitochondrial gas pedal. IUBMB Life 65:180-190

18. Mathiesen C, Caesar K, Thomsen K, Hoogland TM, Witgen BM, Brazhe A, Lauritzen M (2011) Activity-dependent increases in local oxygen consumption correlate with postsynaptic currents in the mouse cerebellum in vivo. J Neurosci 31:18327-18337

19. Llorente-Folch I, Rueda CB, Amigo I, del Arco A, Saheki T, Pardo B, Satrustegui J (2013) Calcium-regulation of mitochondrial respiration maintains ATP homeostasis and requires ARALAR/AGC1-malate aspartate shuttle in intact cortical neurons. J Neurosci 33(13957-13971):13971a
20. Pardo B, Contreras L, Serrano A, Ramos M, Kobayashi K, Iijima M, Saheki T, Satrustegui J (2006) Essential role of aralar in the transduction of small $\mathrm{Ca}^{2+}$ signals to neuronal mitochondria. J Biol Chem 281:1039-1047

21. Llorente-Folch I, Rueda CB, Pardo B, Szabadkai G, Duchen MR, Satrustegui J (2015) The regulation of neuronal mitochondrial metabolism by calcium. J Physiol (Lond). doi:10.1113/JP270254

22. Rueda CB, Llorente-Folch I, Amigo I, Contreras L, GonzalezSanchez P, Martinez-Valero P, Juaristi I, Pardo B, del Arco A, Satrustegui J (2014) $\mathrm{Ca}(2+)$ regulation of mitochondrial function in neurons. Biochim Biophys Acta 1837:1617-1624

23. O’Donnell JM, Kudej RK, LaNoue KF, Vatner SF, Lewandowski ED (2004) Limited transfer of cytosolic NADH into mitochondria at high cardiac workload. Am J Physiol Heart Circ Physiol 286: H2237-H2242

24. O'Donnell JM, Doumen C, LaNoue KF, White LT, Yu X, Alpert NM, Lewandowski ED (1998) Dehydrogenase regulation of metabolite oxidation and efflux from mitochondria in intact hearts. Am J Physiol 274:H467-H476

25. McCormack JG, Denton RM (1979) The effects of calcium ions and adenine nucleotides on the activity of pig heart 2-oxoglutarate dehydrogenase complex. Biochem J 180:533-544

26. Sluse FE, Goffart G, Liebecq C (1973) Mechanism of the exchanges catalysed by the oxoglutarate translocator of rat-heart mitochondria. Kinetics of the external-product inhibition. Eur J Biochem/FEBS 32:283-291

27. Porras OH, Loaiza A, Barros LF (2004) Glutamate mediates acute glucose transport inhibition in hippocampal neurons. J Neurosci 24:9669-9673

28. Bak LK, Walls AB, Schousboe A, Ring A, Sonnewald U, Waagepetersen HS (2009) Neuronal glucose but not lactate utilization is positively correlated with NMDA-induced neurotransmission and fluctuations in cytosolic $\mathrm{Ca}^{2+}$ levels. J Neurochem 109: 87-93

29. Bak LK, Obel LF, Walls AB, Schousboe A, Faek SAA, Jajo FS, Waagepetersen HS (2012) Novel model of neuronal bioenergetics: postsynaptic utilization of glucose but not lactate correlates positively with $\mathrm{Ca}^{2+}$ signalling in cultured mouse glutamatergic neurons. Asn Neuro. doi:10.1042/AN20120004

30. Fox PT, Raichle ME, Mintun MA, Dence C (1988) Nonoxidative glucose consumption during focal physiologic neural activity. Science 241:462-464

31. Caesar K, Hashemi P, Douhou A, Bonvento G, Boutelle MG, Walls AB, Lauritzen M (2008) Glutamate receptor-dependent increments in lactate, glucose and oxygen metabolism evoked in rat cerebellum in vivo. J Physiol 586:1337-1349

32. Bak LK, Schousboe A, Sonnewald U, Waagepetersen HS (2006) Glucose is necessary to maintain neurotransmitter homeostasis during synaptic activity in cultured glutamatergic neurons. J Cerebr Blood F Met 26:1285-1297

33. Pellerin L, Magistretti PJ (2012) Sweet sixteen for ANLS. J Cereb Blood Flow Metab 32:1152-1166

34. Hertz L, Gibbs ME, Dienel GA (2014) Fluxes of lactate into, from, and among gap junction-coupled astrocytes and their interaction with noradrenaline. Front Neurosci 8:261

35. Yang J, Ruchti E, Petit JM, Jourdain P, Grenningloh G, Allaman I, Magistretti PJ (2014) Lactate promotes plasticity gene expression by potentiating NMDA signaling in neurons. Proc Natl Acad Sci USA 111:12228-12233

36. Hirrlinger J, Nave KA (2014) Adapting brain metabolism to myelination and long-range signal transduction. Glia 62:17491761

37. Funfschilling U, Supplie LM, Mahad D, Boretius S, Saab AS, Edgar J, Brinkmann BG, Kassmann CM, Tzvetanova ID, Mobius W, Diaz F, Meijer D, Suter U, Hamprecht B, Sereda MW, Moraes CT, Frahm J, Goebbels S, Nave KA (2012) Glycolytic 
oligodendrocytes maintain myelin and long-term axonal integrity. Nature 485:517-521

38. Jackson JG, O'Donnell JC, Takano H, Coulter DA, Robinson MB (2014) Neuronal activity and glutamate uptake decrease mitochondrial mobility in astrocytes and position mitochondria near glutamate transporters. J Neurosci 34:1613-1624

39. Johnson DT, Harris RA, French S, Blair PV, You J, Bemis KG, Wang M, Balaban RS (2007) Tissue heterogeneity of the mammalian mitochondrial proteome. Am J Physiol Cell Physiol 292: C689-C697

40. Johnson DT, Harris RA, Blair PV, Balaban RS (2007) Functional consequences of mitochondrial proteome heterogeneity. Am J Physiol Cell Physiol 292:C698-C707

41. Waagepetersen HS, Hansen GH, Fenger K, Lindsay JG, Gibson G, Schousboe A (2006) Cellular mitochondrial heterogeneity in cultured astrocytes as demonstrated by immunogold labeling of alpha-ketoglutarate dehydrogenase. Glia 53:225-231

42. Waagepetersen HS, Sonnewald U, Schousboe A (2003) Compartmentation of glutamine, glutamate, and GABA metabolism in neurons and astrocytes: functional implications. Neuroscientist 9:398-403

43. Macaskill AF, Rinholm JE, Twelvetrees AE, Arancibia-Carcamo IL, Muir J, Fransson A, Aspenstrom P, Attwell D, Kittler JT (2009) Miro1 is a calcium sensor for glutamate receptor-dependent localization of mitochondria at synapses. Neuron 61:541-555

44. Dienel GA, McKenna MC (2014) A dogma-breaking concept: glutamate oxidation in astrocytes is the source of lactate during aerobic glycolysis in resting subjects. J Neurochem 131:395-398

45. Dienel GA (2014) Lactate shuttling and lactate use as fuel after traumatic brain injury: metabolic considerations. J Cereb Blood Flow Metab 34:1736-1748
46. Dienel GA (2012) Brain lactate metabolism: the discoveries and the controversies. J Cereb Blood Flow Metab 32:1107-1138

47. Dienel GA, Cruz NF (2009) Exchange-mediated dilution of brain lactate specific activity: implications for the origin of glutamate dilution and the contributions of glutamine dilution and other pathways. J Neurochem 109(Suppl 1):30-37

48. Pellerin L, Magistretti PJ (1994) Glutamate uptake into astrocytes stimulates aerobic glycolysis: a mechanism coupling neuronal activity to glucose utilization. Proc Natl Acad Sci USA 91: 10625-10629

49. Ivanov AI, Malkov AE, Waseem T, Mukhtarov M, Buldakova S, Gubkina O, Zilberter M, Zilberter Y (2014) Glycolysis and oxidative phosphorylation in neurons and astrocytes during network activity in hippocampal slices. J Cereb Blood Flow Metab 34:397-407

50. Patel AB, Lai JC, Chowdhury GM, Hyder F, Rothman DL, Shulman RG, Behar KL (2014) Direct evidence for activity-dependent glucose phosphorylation in neurons with implications for the astrocyte-to-neuron lactate shuttle. Proc Natl Acad Sci USA 111:5385-5390

51. Lewandowski ED, O’Donnell JM, Scholz TD, Sorokina N, Buttrick PM (2007) Recruitment of NADH shuttling in pressureoverloaded and hypertrophic rat hearts. Am J Physiol Cell Physiol 292:C1880-C1886

52. Josan S, Park JM, Hurd R, Yen YF, Pfefferbaum A, Spielman D, Mayer D (2013) In vivo investigation of cardiac metabolism in the rat using MRS of hyperpolarized [1-13C] and [2-13C]pyruvate. NMR Biomed 26:1680-1687 